\title{
Polymer Blended (Epoxy/Vinylester) Nanocomposites Resistance against Pulling \& Sliding Wear Loads
}

\author{
P. Harisankar ${ }^{1, *}$, Y. V. Mohana Reddy ${ }^{1}$, K. Hemachandra Reddy ${ }^{2}$ \\ ${ }^{1}$ Department of Mechanical Engineering, G. Pulla Reddy Engineering College, Nandyal Road, \\ Kurnool - 518007, Andhra Pradesh, India \\ ${ }^{2}$ Department of Mechanical Engineering, Jawaharlal Nehru Technological University Anantapur, \\ Anantapur - 515002, Andhra Pradesh, India \\ *E-mail address: pallahharisankar1@ gmail.com
}

\begin{abstract}
This paper discloses the development and synthesis of polymer blended nanocomposites filled with nanoclay. The hybridization of epoxy is mixed with vinylester resin (VER) to prepare polymer blend filled with organoclay was studied to enhance mechanical properties of epoxy/VER. Clay loading was done in such a way that with different wt. proportions viz.1, 1.5, 2.0, 2.5, 3.0, 4.0, 5.0, \& $7.5 \mathrm{w} \%$ ratios. Appropriately cured samples gave excellent mechanical and tribological properties. Results showed that the tensile strength of the composites increased with increase in filler content for the range of filler contents (2.5-4\% vol.). The results indicated that at $4 \% \mathrm{wt}$. of filler concentration the tensile strength obtained is good i.e. $47.79 \mathrm{MPa}$ with density $1.37 \mathrm{gm} / \mathrm{cm}^{3}$ and hardness 45.5 . Dry Sliding wear tests were also conducted by following a well-planned experimental schedule based on Taguchi's design of experiments, considering parameters like Filler content, Normal load, Sliding Velocity and Sliding distance, on a Pin-On-Disc set-up (ASTM G-99 standard, Make: DUCOM Engineers, Bangalore, India). In the experimentation composite pins were worn against a rotating steel disc (Europe Norm) EN-31, (Rockwell C Hardness) HRC 60 and (Roughness Average) Ra 0.02 microns. Control factors like Filler Content, Normal Load were found to be significant factors affecting the Wear rate i.e. the inclusion of nanoclay as filler found to be contributed in improving the wear resistance of the composite. SEM observations are made to probe the wear mechanisms involved.
\end{abstract}

Keywords: blended Polymer composite; vinylester; epoxy; Mechanical properties; Sliding Wear; Taguchi Method; SEM

\section{INTRODUCTION}

Recent developments in nanotechnology have provided several routes to prepare nanocomposites. What differentiates nanocomposites materials from classical composites is the degree of control of fabrication, processing and performance that can be achieved nearly down to the atomic scale. Thermoplastics occupy only a small percentage of the advanced composite market, while thermoset (i.e. Epoxy) materials contribute to more than 70 per cent. Due to their inbuilt entanglement structure, these resins are the most important polymers when it comes to high performance. Epoxy is a versatile and widely accepted matrix material 
for fabrication of advanced composites, hardware components, electrical circuit board materials and missile equipments, because of its excellent bonding, thermal, mechanical, dielectric and aging characteristics. Epoxy resins are widely used as coatings, adhesives, moulding compounds, and polymer composites because of their superior thermomechanical properties and excellent processability. However, the use of thermoset materials is often limited because of low toughness property.

Therefore, when the bulk amounts of epoxies are used, usually it will blend with toughening agents. Vinyl esters toughening agent which will be used along with epoxy materials. However, these particles always affect the processability of the system. Because of the flexibility present in the structure of epoxy, it could be used as one of the blend component in this study. It also has large numbers of epoxy and hydroxyl groups, which may take part in cross-linking reactions with oil-modified vinylester resins. To improve its performance characteristics in advanced engineering applications, toughening of epoxy material is essential to improve its hardness and tensile strength. The hardness of the epoxy resin has been increased by blending it with flexible polymers and elastomers [1-5]. However, modification of epoxy resin with elastomers improves its hardness and impact strength properties with decrease in some of the physical properties of the cured epoxy at higher temperatures. Hence, a suitable polymeric material is needed to improve the impact resistance, stress-strain properties by retaining stiffness, glass transition temperature and thermal stability of the epoxy resin. To achieve this, development of an inter-cross-linked polymer network of thermoset-thermoset blends have been extensively studied due to their enhanced mechanical properties. Among various polymer blends, modifications of epoxy with polyester matrix combinations are an attractive route to promote the performance of the thermoset matrix. VER is widely used thermosetting materials because of their low cost and good combination of properties, including chemical resistance, mechanical and thermal properties. VER is the addition product of an epoxy resin with unsaturated carboxylic acid such as acrylic or methacrylicacid. As a result, a pendant hydroxyl groups and terminal unsaturation groups are produced.

The hydroxyl groups enhance the polarity of VER and facilitate adhesion and pigment wetting properties. Neat VERs has always high viscosity, due to the aromatic nature of the aromatic structure, which led the wetting of the fibers in fiber reinforced plastics (FRP). As a result, vinyl monomers such as styrene or methyl methacrylate (MMA) are used to dilute VER [6-7]. The blending technique may be used effectively to overcome the inferior properties of both the components. Miscible polymer blends produce a newly improved material from less superior individual components. Again, because of the enhancement of the properties, such as the mechanical, thermal, and barrier properties, even at low concentrations, the nanocomposites of such blends have drawn much attention [8-19]. The primary goal of this research is to develop the polymer blended nanocomposites and then to characterize thereof. Authors focued to determine the effect of load on tensile strength (TS), wear rate, hardness and morphological studies of the nanocomposite. The main focus of the work was to investigate the compatibility effect of miscible epoxy/vinylester nanocomposite blends on mechanical and morphology properties. For this purpose a blend of epoxy/vinylester $(80 / 20 \% \mathrm{w} / \mathrm{w})$ polymers were prepared as a function of nanoclay in different weight ratios such as $0,1,1.5,2.0,2.5,3,4,5$ and $7.5 \%$. 


\section{EXPERIMENTAL.}

\section{1. Materials and Methods.}

The resins used in this study were (i) Epoxy (Ciba-Geigy, Araldite-LY 556 and Amine hardener HY-951) with the resin-hardener ratio as 100:10 and (ii) 2,2-di[4-(3-acryloyloxy-2hydroxy-n-propoxy)phenyl] propane (VER prepolymer) and $N, N$-dimethyl- $N$-(4vinylbenzyl)stearyl ammonium modified montmorillonite (VSA-MMT) were prepared according to the procedure described in our previous paper [20]. Benzoyl peroxide was purchased from Kishida Co. Japan and used as received. Tetrahydrofuran (THF) was used as received from Tokyo Kasei. Methyl methacrylate (MMA) is commercial supplied from Aldrich and used after removing the inhibitor by washing with $1 \mathrm{M}$ aqueous $\mathrm{NaOH}$ solution followed by drying over anhydrous sodium sulfate.

\section{2. Blended polymer Nanocomposite Preparation}

Pre-calculated amount of clay and epoxy/ VER (i.e. 80/20\% w/w ratio) were mixed together in a suitable beaker with mechanical stirrer. Clay was mixed in stipulated quantity to the epoxy/VER blend and was mixed thoroughly with mechanical shear stirrer for about $1 \mathrm{hr}$. at ambient temperature conditions. Then the mixture was placed in a high intensity ultrasonicator for one and half hour with pulse mode (15s on / $15 \mathrm{~s}$ off). External cooling system was employed by submerging the beaker containing the mixture in an ice bath to avoid temperature rise during the sonication process, followed by stirring overnight to obtain a homogeneous and stable suspension.

Once the process was completed, hardener/catalyst/ promoter $(100: 10 / 2 / 2)$ parts by weight was added to the modified epoxy/vinylester mixture. $0.05 \mathrm{~g}$ of benzoyl peroxide was added as free radical initiator followed by stirring for $30 \mathrm{~min}$. The mixture was cast-over pretreated glass plate, followed by drying at $60{ }^{\circ} \mathrm{C}$ for $5 \mathrm{~h}$ to remove the solvent. The hybrid film as fixed on glass plate was cured at $80{ }^{\circ} \mathrm{C}, 100{ }^{\circ} \mathrm{C}, 120^{\circ} \mathrm{C}$ and finally post cured at 160 ${ }^{\circ} \mathrm{C}$ for $2 \mathrm{~h}$ each to give transparent film of VER $/ 20 \%$ Epoxy $/ 80 \%$ - MMT.A glass mould with required dimensions was used for making samples on par with ASTM standards [15].

The glass mould was coated with mould releasing agent to enable easy removal of the sample. The nanocomposite mixture was poured over the glass mould. Brush and roller was used to impregnate the nanocomposite. The closed mould was kept under pressure for $24 \mathrm{hrs}$ at room temperature. To ensure complete curing the blended nanocomposite samples were post cured at $70{ }^{\circ} \mathrm{C}$ for $1 \mathrm{hr}$. and the test specimens of required sizes were cut out from the sample sheet.

\section{3. Mechanical Testing}

The specimens were tested using Instron UTM testing machine at Polymer Science department, SK University, Anantapur, AP India. The parameters such as Hardness, Density and Tensile strength were tested. Tensile Testing is done using machine manufactured by Durga Engineers, as per standard ASTM D638.

For Tensile Testing Dimensions of the specimen used: As per ASTM D638 Type 1, Test Condition: Temperature $24 \pm 1{ }^{\circ} \mathrm{C} /$ humidity $55 \pm 5$, Tensile Speed: 50 . Density testing is done using machine manufactured by Shimadzu Densitometer as per ASTM D792. Hardness Testing is done using machine manufactured by Colman-GYZJ-934-1 as per ASTM D2583.A11. 


\section{4. Tribological Testing}

Epoxy/VER blend solutions were prepared then of the filler nanoclay is added mechanically and stirred gently into the blend solution, care to be taken to avoid the introduction of air bubbles and even dispersion of filler. The HY-951 hardener is added to the above mixture in the required ratio. Once the process was completed, hardener/catalyst/ promoter $(100: 10 / 2 / 2)$ parts by weight was added to the modified epoxy/vinylester mixture $0.05 \mathrm{~g}$ of benzoyl peroxide was added as free radical initiator followed by stirring for $30 \mathrm{~min}$. The mixture is then poured into a metallic mold cavity coated with a silicon release agent to yield specimens of $10 \mathrm{~mm}$ diameter and $30 \mathrm{~mm}$ length. The mould is placed in an electric oven and heated at constant temperature of $180^{\circ} \mathrm{C}$ for one Hour of curing and upon curing the split mould is opened to release specimens from the mold after 30 minutes. These test specimens were then post cured at constant temperature of $100{ }^{\circ} \mathrm{C}$ in an electric oven for one Hour.

\section{5. The Wear Test Set-Up}

A Pin-on-Disc set-up (ASTM G-99 standard, Make: DUCOM Engineers, Bangalore, India) is used for slide wear tests. Composite specimens $10 \mathrm{~mm}$ diameter and $30 \mathrm{~mm}$ length, which come in contact with a rotating steel disc (EN31) with HRC 60 and surface roughness (Ra) 0.02 microns. The wear was measured by loss of weight of specimen in gms, using the electronic weighing apparatus with least count 0.01 gms of make E.G. Kantawala Pvt. Ltd., Model: Jewel 3. Equations used for calculation of specific wear were as per the literature survey [1]

\section{6. Taguchi Experimental Design}

Taguchi's experimental design is a powerful analysis tool for modeling and analyzing the influence of control factors on performance output. The wear tests on the composites are carried out under different operating conditions considering Four parameters, viz Filler content, Normal Load, Sliding Velocity and Sliding distance each at four levels as listed in table no: 4 in accordance with Taguchi's L16 orthogonal array. The impacts of these four parameters are studied using this L16 array and the tests are conducted as per the experimental design. The experimental observations are further transformed into signal-tonoise $(\mathrm{S} / \mathrm{N})$ ratios. The $\mathrm{S} / \mathrm{N}$ ratio for minimum wear rate can be expressed as "smaller is better" characteristic and is calculated as follows.

$$
\mathrm{n}=-10 \log 1 / \mathrm{n}\left(\sum \mathrm{y}^{2}\right)
$$

where ' $\mathrm{n}$ ' is the number of observations, and $\mathrm{y}$ is the observed data. Taguchi's factorial design approach reduces experimentation effort to only 16 runs offering a great advantage in terms of experimental time and cost [20].

\section{RESULTS AND DISCUSSIONS}

\section{1. Mechanical Properties}

The hardness is measured by using Barcol Hardness Tester. The specimen is placed under the indenter of the Barcol hardness tester and a uniform pressure is applied to the specimen until the dial indication reaches a maximum. The depth of the penetration is 
converted into absolute Barcol numbers. Data is expressed as Barcol numbers given by the instrument. Fig. 1 shows the hardness of bare polymer is about 29 but when the filler nanoclay is added to the resin there is increase in hardness. Hardness value is optimized at 4 $\% \mathrm{wt} \%$ of filler, followed by decrease in hardness magnitude due to increase in viscosity of the mixture makes entrapment of air in the composite and consequently unable to transfer the stress due to hollow space initiates the crack.

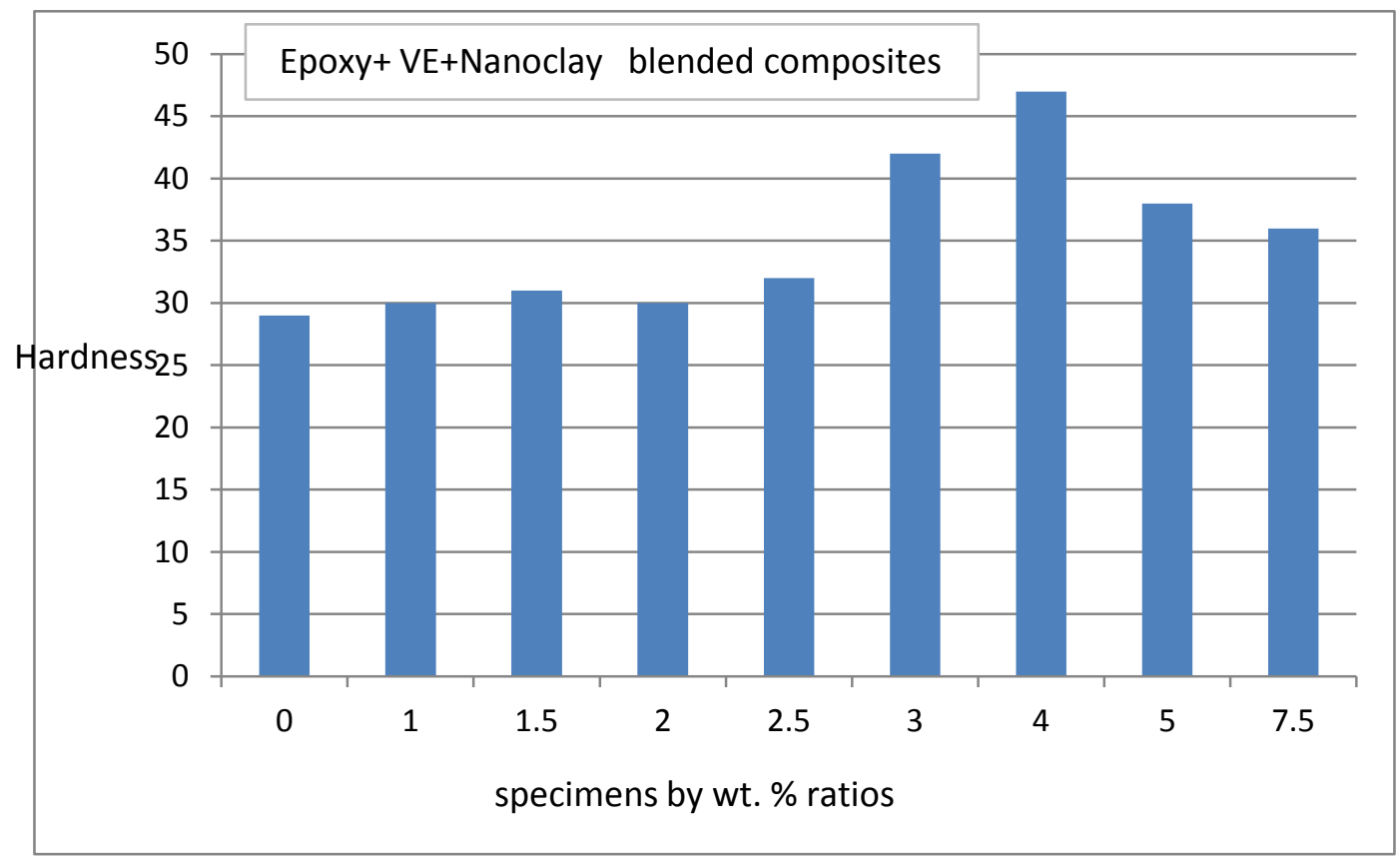

Figure 1. Variation of Hardness at different wt. \% samples of blended nanocomposites.

Density of the synthesized polymer blend nanocomposite appeared to be more with filler vol. $\%$ by virtue of higher density of filler compared to bare polymer. The experimentally observed values of density were further used to calculate wear volume. The slight variation in density measurement was due to the cut piece of the sample considered and an average value has been shown in the Fig. 2.

The tensile strength of bare polymer is $25.69 \mathrm{MPa}$ and this value distinctly increases as filler wt. \% goes on increasing. Maximum tensile strength was observed at 4 wt. $\%$ of filler concentration, which is $46.79 \mathrm{MPa}$. However further filler addition shows decrease in the tensile strength as can be seen in Fig. 3. It can be seen from the same figure that 4 wt. \% filler added to the blended nanocomposite exhibits excellent results.

The tensile strength at $4 \mathrm{wt}$. \% filler concentration in composite is $46.79 \mathrm{MPa}$ with density $1.37 \mathrm{gm} / \mathrm{cm}^{3}$ and showed almost no change in hardness of 24, which can be suggested for variety of industrial applications. Tensile strength of the polymer composite is also depending upon strength at the interface of matrix and filler material. Initially the tensile strength increases with increasing filler material but as filler materials occupies relatively higher wt. $\%$, mechanically mixed composites showed gradually decrease in tensile strength beyond $4 \mathrm{wt} \%$ of filler material.

The similar trend of increase in the tensile strength with filler material is reported in $[1,7]$. 


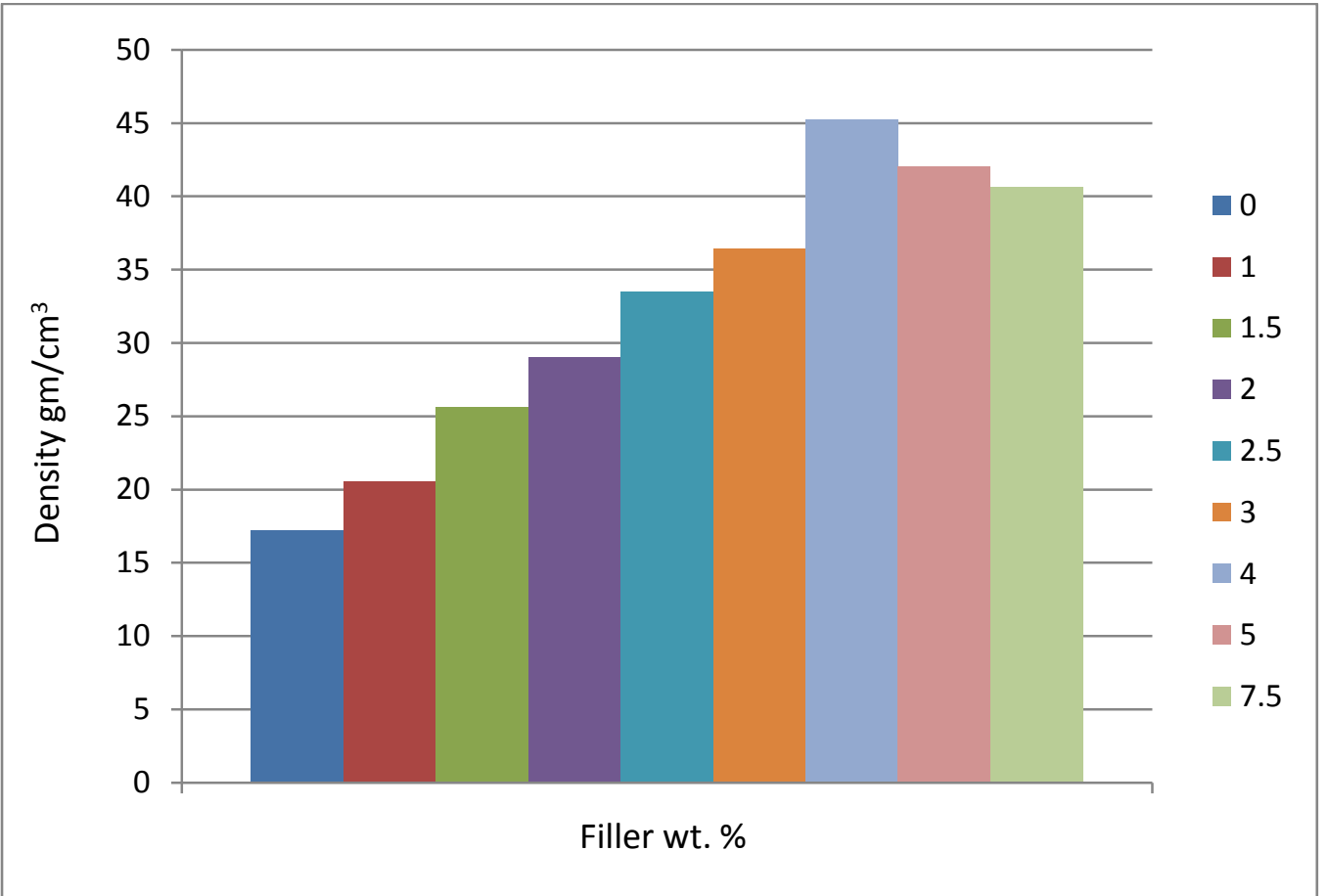

Figure 2. Variation of Density at Different samples of blended nanocomposites.

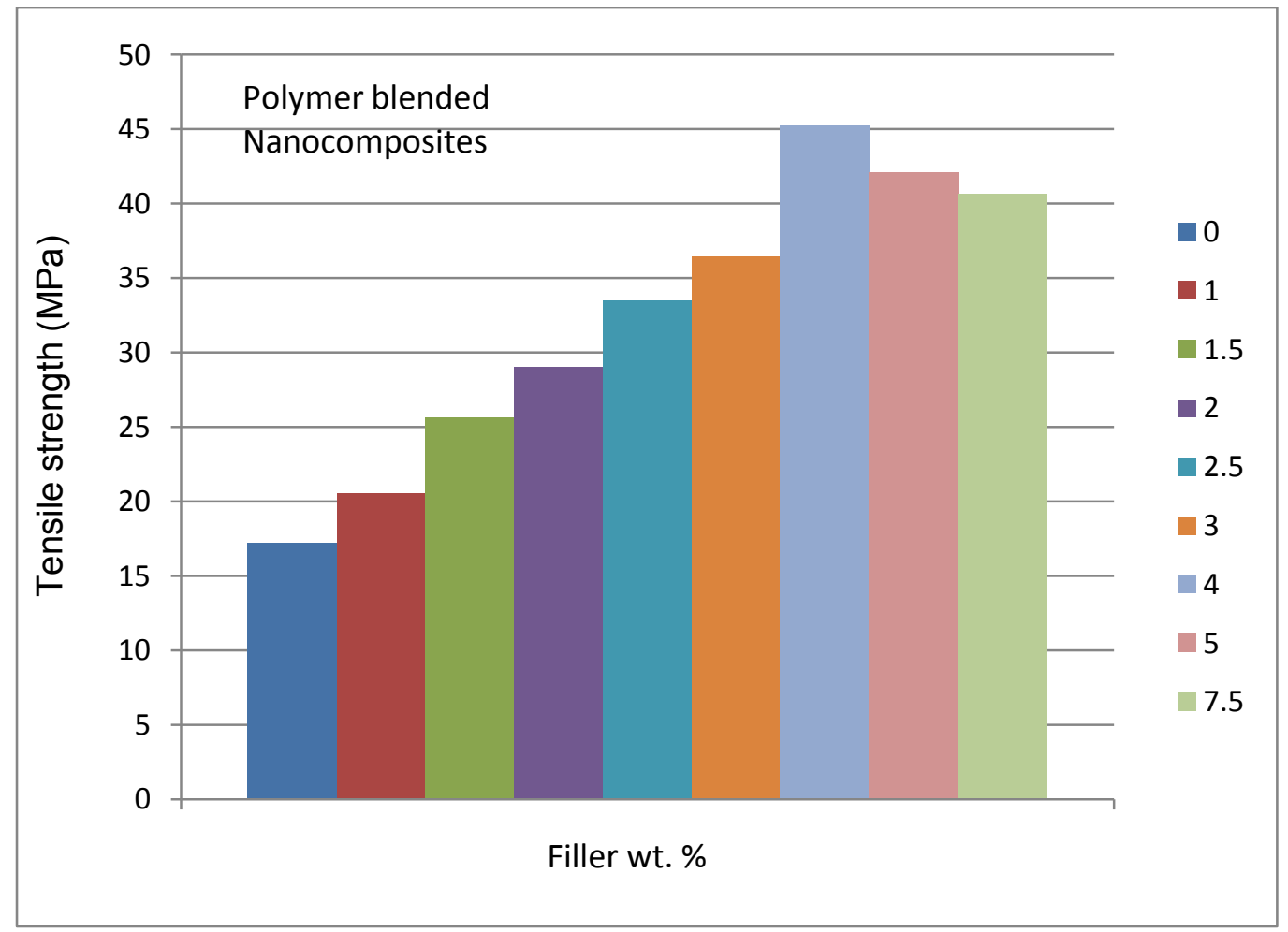

Figure 3. Variation of Tensile strength at different Filler wt. \% ratios of blended nanocomposites. 
On the basis of significant increase in tensile strength wear experiment were focused up to $4 \mathrm{wt} \%$ of filler. The experimental results above revealed that addition of clay in blend have a significant effect on mechanical properties of the Composites.

\section{2. Tribological Properties}

Four levels of filler contents were sorted out to cover the both relatively low and higher tensile strength observed, such a selection of level was exercised to study the effect of tensile strength. The wear rates obtained for all the 16 test runs along with the corresponding $\mathrm{S} / \mathrm{N}$ ratio are presented in the Table 3. From this table the overall mean of the $\mathrm{S} / \mathrm{N}$ ratio of wear rate is found to be 85.75. This is done using MINITAB software used for Design of Experiments application. The $\mathrm{S} / \mathrm{N}$ ratio response analysis show that among all the factors, filler content is the most significant factor followed by normal load, sliding velocity while the sliding distance has the least or almost no significant effect on wear rate of the clay filled Composite under investigation shown in the Fig. 8.

To assesses the effects of individual control factor and the results of response analysis lead to the conclusion that factor combination A4, B3, C4, D3, gives minimum wear. Wear of a material invariably is dictated by relative motion (sliding velocity), normal load and tribopair in terms of material configuration for the given sliding distance. In the present investigation wear of polymer composite with varying filler content has been reported at the given sliding velocity, normal load and sliding distance and the experimental data generated has been reported in Table 1. Increased hardness and tensile strength with increasing filler percentage provide relatively better mechanical properties (Hardness and Tensile strength), Figs. $1 \& 3$. From the experimental data, it is revealed that filler content is most predominant factor contributing to resistance against the wear, across the given normal load, sliding velocity and sliding distance.

Table 1. Design Matrix (Experimental results).

\begin{tabular}{|c|c|c|c|c|c|c|}
\hline $\begin{array}{c}\text { Exp. } \\
\text { No. }\end{array}$ & $\begin{array}{c}\text { Sliding } \\
\text { Velocity } \\
(\mathrm{m} / \mathrm{sec})\end{array}$ & $\begin{array}{c}\text { Normal } \\
\text { Load (N) }\end{array}$ & $\begin{array}{c}\text { Filler } \\
\text { content } \\
(\text { wt. \%) }\end{array}$ & $\begin{array}{c}\text { Sliding } \\
\text { Distance } \\
(\mathrm{m})\end{array}$ & $\begin{array}{c}\text { Sp. Wear rate } \\
\left(\mathrm{mm}^{3} / \mathrm{N}-\mathrm{m}\right)\end{array}$ & $\begin{array}{c}\text { S-N ratio } \\
(\mathrm{db})\end{array}$ \\
\hline 1 & 1.32 & 30.21 & 1 & 1600 & $0.194 \times 10-^{3}$ & 77.23 \\
2 & 1.32 & 40.35 & 2 & 2100 & $0.234 \times 10-^{3}$ & 77.10 \\
3 & 1.32 & 50.06 & 3 & 2600 & $0.023 \times 10-^{3}$ & 85.41 \\
4 & 1.32 & 59.07 & 4 & 3000 & $0.0342 \times 10-^{3}$ & 89.75 \\
\hline 5 & 2.63 & 30.21 & 2 & 2600 & $0.0856 \times 10-^{3}$ & 80.63 \\
6 & 2.63 & 40.35 & 1 & 3000 & $0.053 \times 10-^{3}$ & 60.28 \\
7 & 2.63 & 50.06 & 4 & 1600 & $0.0915 \times 10-^{3}$ & 81.95 \\
\hline 10 & 2.63 & 59.07 & 3 & 2100 & $0.0632 \times 10-^{3}$ & 85.74 \\
11 & 3.42 & 30.21 & 3 & 3000 & $0.124 \times 10-^{3}$ & 79.12 \\
12 & 3.42 & 40.35 & 4 & 2600 & $0.0342 \times 10-^{3}$ & 90.56 \\
\hline 13 & 3.42 & 50.06 & 1 & 2100 & $0.124 \times 10-^{3}$ & 78.96 \\
14 & 3.42 & 59.07 & 2 & 1600 & $0.194 \times 10-^{3}$ & 79.26 \\
15 & 5.52 & 30.21 & 4 & 2100 & $0.142 \times 10-^{3}$ & 85.42 \\
16 & 5.52 & 40.35 & 3 & 1600 & $0.0567 \times 10-^{3}$ & 84.36 \\
\hline
\end{tabular}


Table 2. Levels of variables used in experiment.

\begin{tabular}{|ccccc|}
\hline Control factors & \multicolumn{4}{c|}{ Levels } \\
\hline Sliding Velocity & 1.32 & 2.63 & 3.42 & 5.5 \\
\hline Normal Load & 30.21 & 40.35 & 50.06 & 59.07 \\
\hline Filler content & 1 & 2 & 3 & 4 \\
\hline Sliding distance & 1600 & 2100 & 2600 & 3000 \\
\hline
\end{tabular}

Table 3. S/N Ratios for Wear Rate.

\begin{tabular}{|c|c|c|c|c|}
\hline Level & $\begin{array}{c}\text { Sliding } \\
\text { Velocity } \\
(\mathrm{m} / \mathrm{sec})\end{array}$ & $\begin{array}{c}\text { Normal } \\
\text { Load (N) }\end{array}$ & $\begin{array}{c}\text { Filler } \\
\text { Content } \\
(\text { wt. } \%)\end{array}$ & $\begin{array}{c}\text { Sliding } \\
\text { Distance (m) }\end{array}$ \\
\hline 1 & 80.42 & 79.65 & 70.5 & 79.56 \\
\hline 2 & 76.24 & 76.23 & 81.23 & 80.32 \\
\hline 3 & 80.22 & 83.42 & 82.63 & 81.27 \\
\hline 4 & 82.53 & 78.99 & 85.23 & 79.54 \\
\hline Delta & 3.2 & 6.5 & 15.2 & 1.96 \\
\hline Rank & 3 & 2 & 1 & 4 \\
\hline
\end{tabular}

The obtained results are attributed to better mechanical properties set(s) observed improvement in wear resistance with filler content has been in papers $[8,17]$. The clay when comes in contact with the counter surface can sustain maximum load over the sliding distance and further clay particles get chipped off. This chipping is clearly seen in the micrograph, Fig. 5(d). Hardness is one of the important mechanical properties dictating performance of the material during service. Improved hardness exhibited better wear resistance in the present investigations also, higher hardness and higher wear resistance has been reported in Fig. 5. Similarly relatively higher density and higher tensile strength also increases the resistance to wear. However the wear phenomenon is subjective to load, sliding velocity and also apart from the material characteristic [1]. In the present investigation also the resistance to wear is observed to be sensitive to mechanical properties and loading conditions as a combined effect. Therefore apart from the maximum predominant factor i.e. filler content other conditions normal load followed by sliding velocity and sliding distance also contributed towards wear rate of the polymer composite, Table 3.

\section{3. Morphological Studies of Worn Surfaces}

The surfaces of the specimen are examined directly with scanning electron microscopy. The material's microstructure plays a major role in determining the wear mechanism in Composite material. The SEM images are taken at R.V College of Engineering, Bangalore. 
In Fig. 4 (a), the SEM morphology of the worn surface, with 1 wt. \% clay as filler and $30.21 \mathrm{~N}$ loads under dry conditions of sliding is characterized by obvious scratching parallel to the sliding direction. Surface shows slightly ploughed marks, formed due to the destruction and transfer of the subsurface, indicating adhesion as the dominant wear mechanism. [21]. At lower particle contents, the dispersion of the particles in the epoxy matrix was not enough, more epoxy matrix was exposed to the rotating steel disc, so the wear rate registered is more. SEM micrographs of Fig. 4(b), shows there is a severe deterioration of the composite surface when applied load is higher and sliding speed gets higher. Small sized platelets and debris found on the worn surface reflects the brittle nature of VER/epoxy blend. Here it is observed that lots of wear debris is produced on the surface which gradually changes to smaller particles, at the beginning the adhesive wear dominates, the micrograph exhibit highest wear due to the fact that wear debris produced acts as third body and abrasive wear occurs which is visible at higher magnifications.

The load carrying capacity of the composite has increased Fig. 5 (c) the worn surface show very small debris removed and surface seen to be smooth, the lower wear rate is due to the formation of the transfer film which is confirmed by the fact that the counterpart wear is absent on the disc. Secondly lower wear is attributed to the lamellar nature of clay. After a prolonged sliding fatigue wear occurs this can be seen in the form of fine debris, in the micrograph. In the filled composite as this Fig. 5 (d) the clay particles congregate on the worn surface, these particles have a function of carrying the load, during sliding they change the friction mode from single macromolecular sliding to a mixture of sliding and rolling friction. Here due to non-uniform dispersion of filler particles as in this case, aggregation of particles at certain pockets have led to brittle fracture and chipping off of the material from the matrix, can be seen in SEM micrograph. Fig. 6 (e) shows the worn surfaces with severe damage characterized by the disintegration of the top layer.

The material removal takes the form of larger blocks, which might be captured between steel counter face and the test pin and abrade the specimen surface leading to more substantial loss. The major craters formed due to fatigue wear, which might have been nucleated subsurface as a result of shear deformation induced by the traction of hard asperities, hence fatigue wear is predominant. Fig. 6 (f) shows micro fractured regions and smeared wear debris particles, which increased with increasing temperature. As the normal load on the particles increased the load distributed over all the asperities and each asperity goes deeper into the surface that means a larger depth of grooves were created as seen in the micrograph. Deeper grooving caused higher wear rate. This resulted in more material removal by a severe plastic deformation, which appeared as a series of grooves parallel to the sliding direction in the SEM micrograph. Fig. 7 (g) the magnified microstructure of the worn surface show wear platelets together with chunks of debris loosely smeared on the worn surface.

The platelets are formed as a result of generation and propagation of surface and subsurface cracks; this debris is generated under repeated loading, indicating the occurrence of surface fatigue delamination process. On the other hand due to good interfacial adhesion between filler and matrix load carrying capacity of the composite is enhanced. Fig. 7 (h) shows the phenomenon of material transfer due to sliding is important because protective third bodies are formed i.e. transfer film formation, the transfer film affects the friction and wear both of the materials by several mechanisms. It isolates the two first bodies from contact minimizes damage due to wear. It controls the friction values usually through interfacial sliding between the transfer film and wear tracks. 

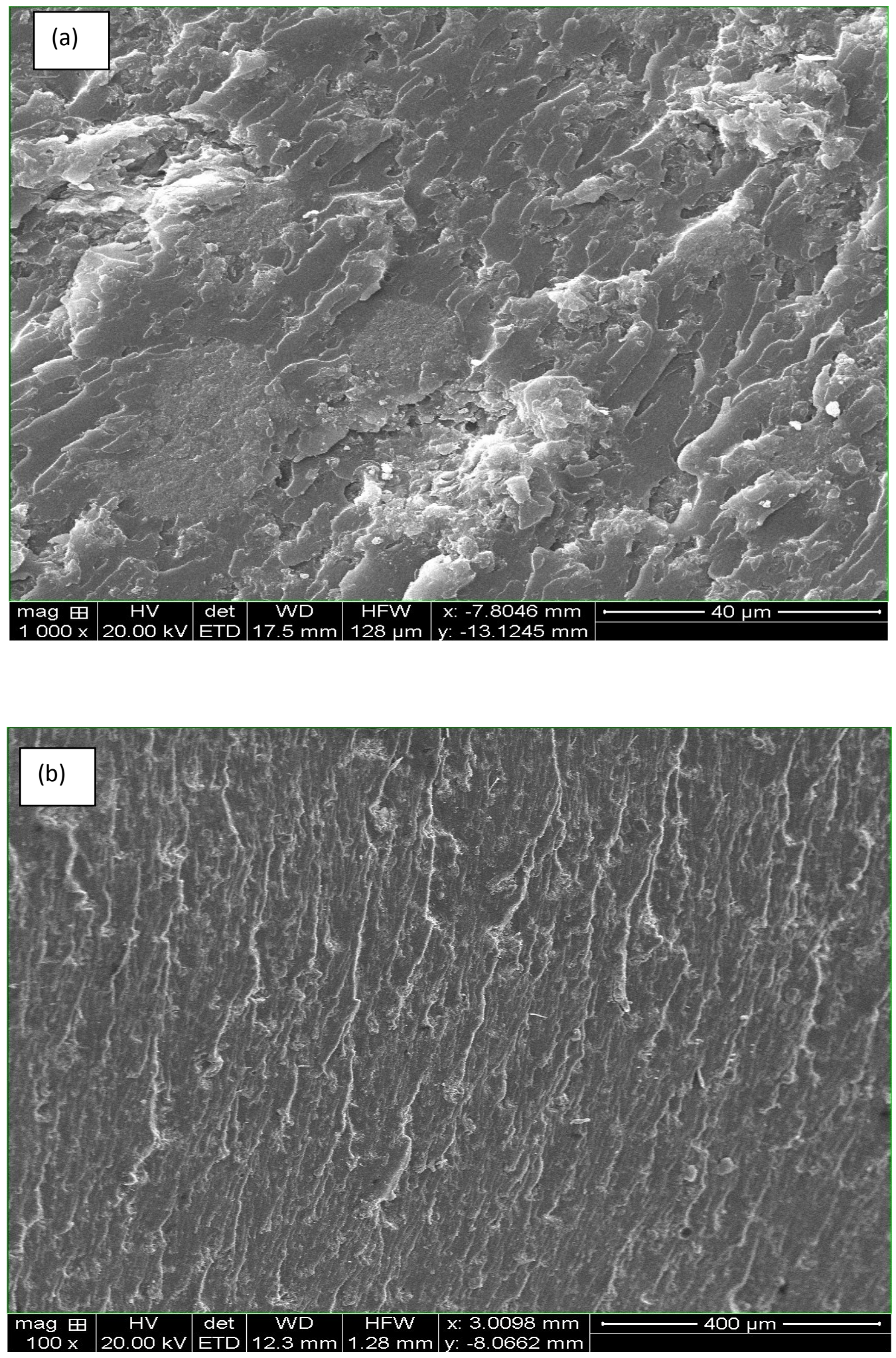

Figure 4. SEM micrographs of the Worn surfaces 1 wt. \% Nanoclay filled Epoxy. a) Worn at 30.21N load (b) Worn at $59.07 \mathrm{~N}$ load. 

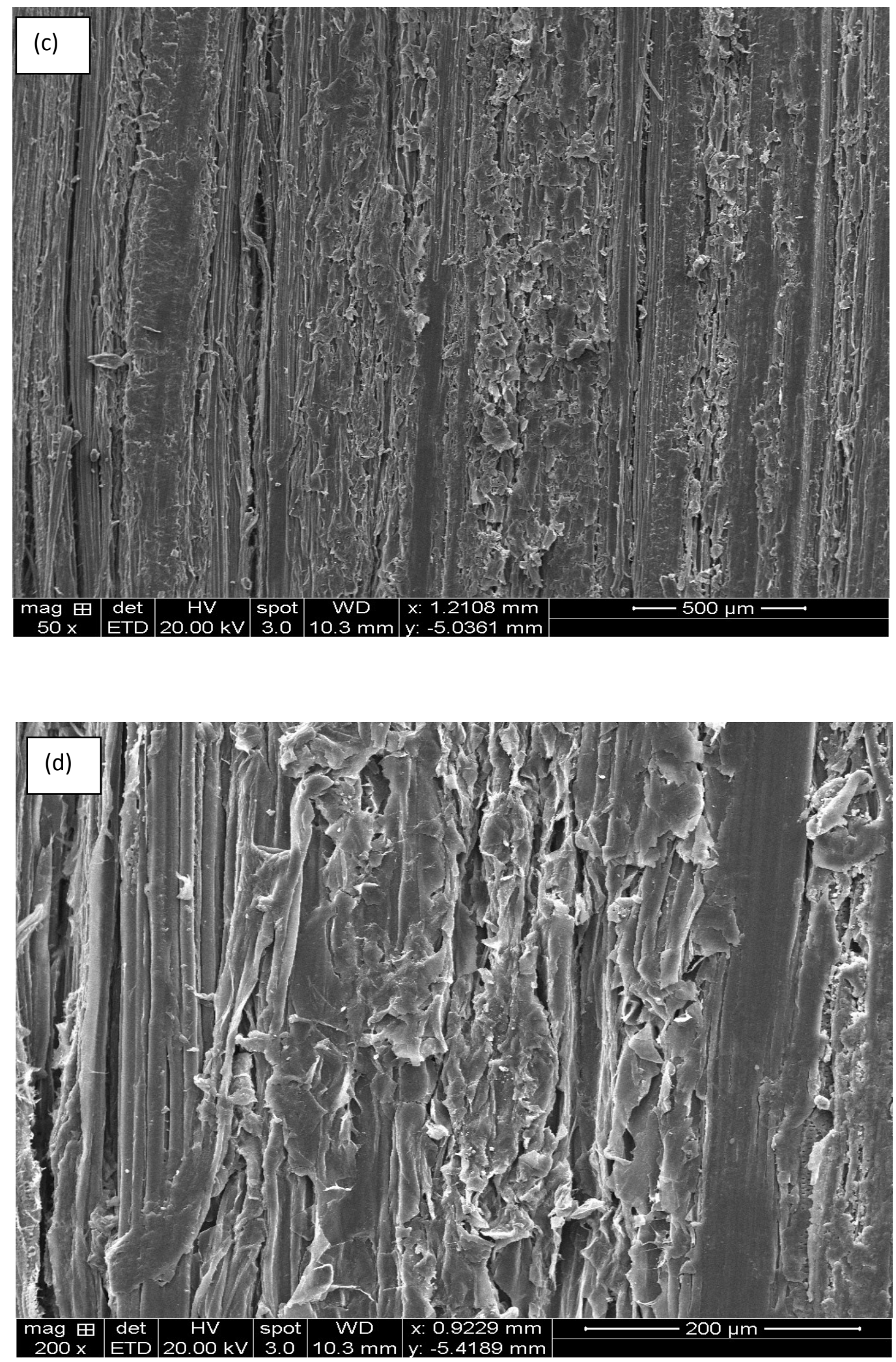

Figure 5. SEM micrographs of the Worn surfaces 2 wt. \% Nanoclay filled Epoxy. c) Worn at 30.21N load (d) Worn at $59.07 \mathrm{~N}$ load. 

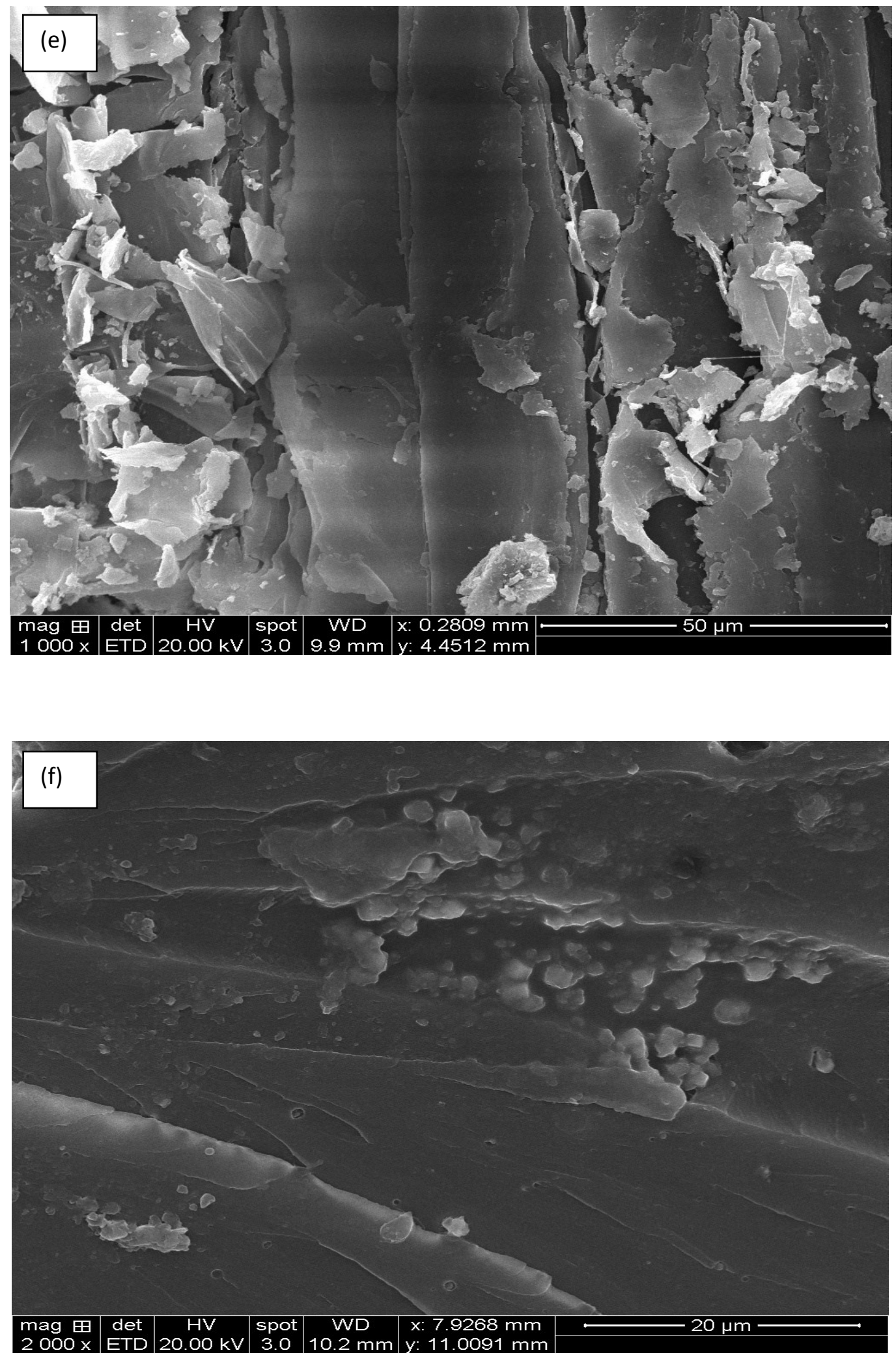

Figure 6. SEM micrographs of the Worn surfaces 3 wt. \% Nanoclay filled Epoxy. e) Worn at 30.21N load (f) Worn at $59.07 \mathrm{~N}$ load. 

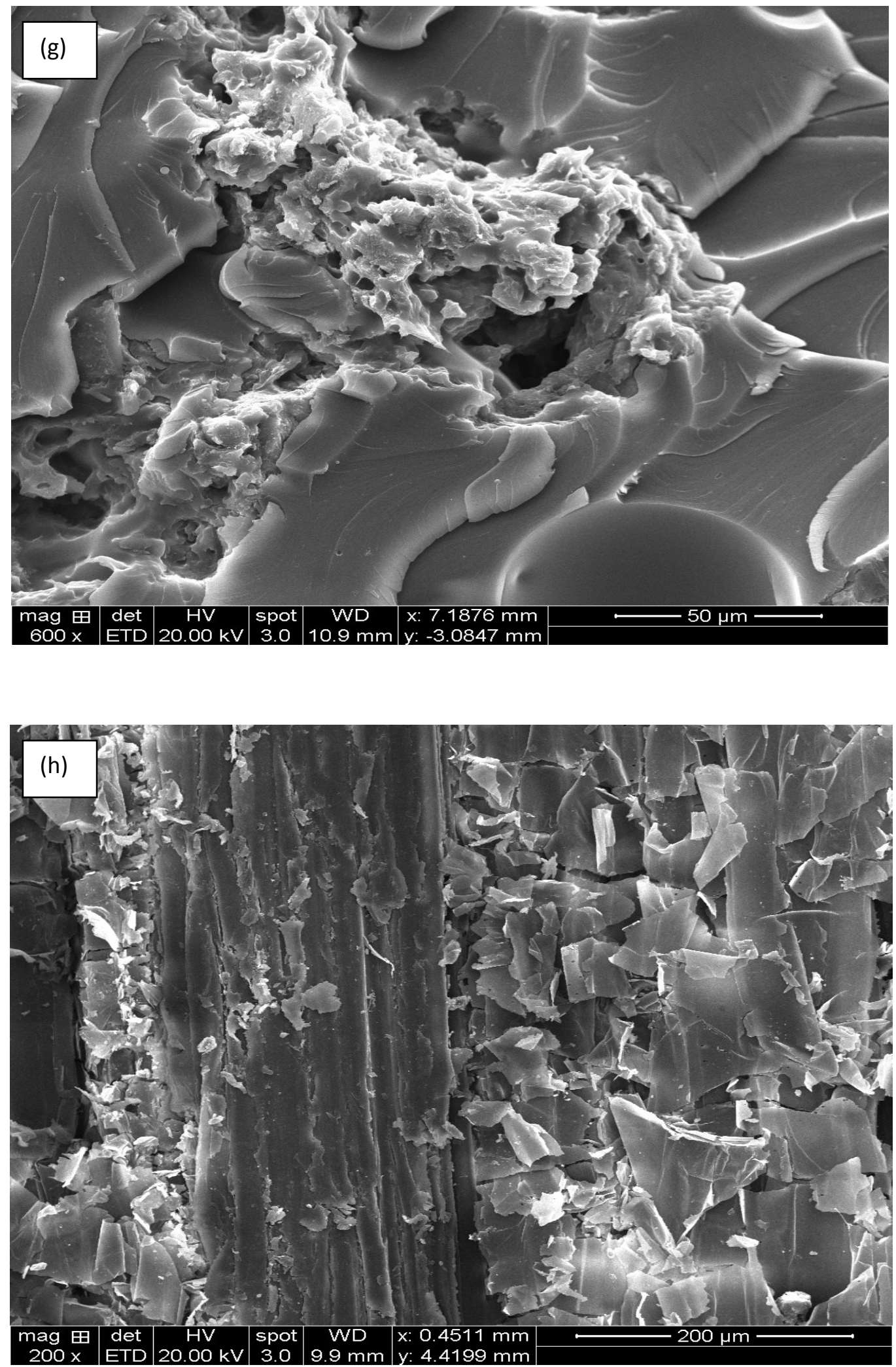

Figure 7. SEM micrographs of the Worn surfaces 4 wt. \% Nanoclay filled Epoxy. g) Worn at $30.21 \mathrm{~N}$ load (h) Worn at $59.07 \mathrm{~N}$ load. 


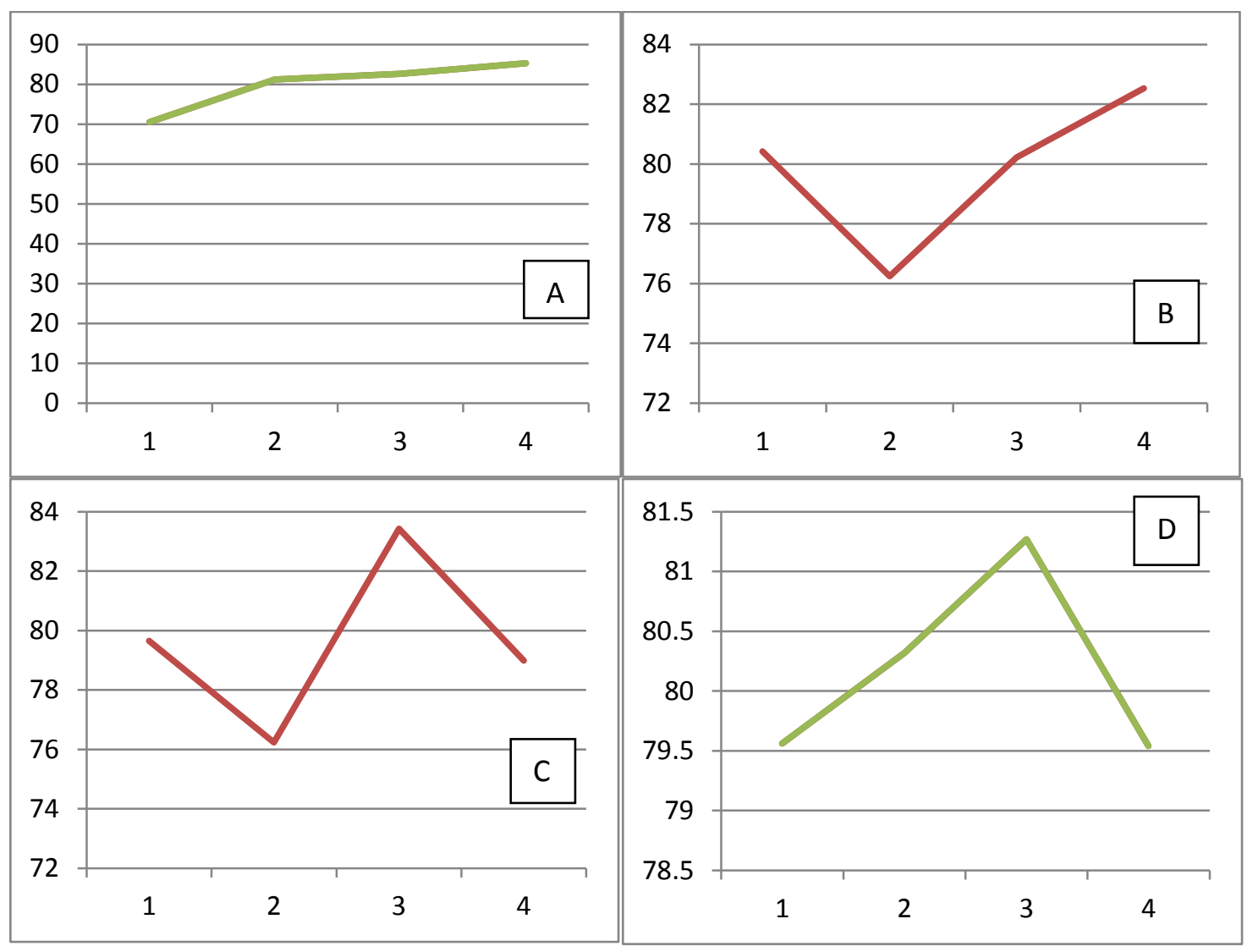

Figure 8. S/N Curves.

Secondly, as filler wt. \% is high enough, abrasive wear dominates, but as the interfacial adhesion between the filler and matrix is good, it results in lower wear. For any given filler content, say $4 \mathrm{wt}$. \%, the mean distance between neighboring particles was smaller than that with the bigger particulates. As the filler have 4 micron uniform sized particles, the greater the number of the particles on the worn surface, the larger the contact area between the particles and the wear pin, and hence the better the wear resistance offered by clay particles.

\section{CONCLUSIONS}

The mechanical characterization of clay reinforced Epoxy/VER nanocomposites bring out the following conclusions. As the percentage of filler increases the hardness also increases, for bare polymer the value is 29 , for the filler $4 \% \mathrm{wt}$. clay it is about 47 . The density also increases as the filler percentage goes on increasing, which is slightly higher at 4 wt. \% clay loading. The tensile strength is increasing as filler wt. \% increases. At 4 wt. \% of clay tensile strength is maximum value. This is the optimum wt. \% of clay, which can be added to this blend, and appropriate applications can be found. But increase in filler makes the tensile strength reduces. Taguchi's method of experimental design is used to find the optimum conditions for dry sliding wear of clay filled blended nanocomposites. Following conclusions are drawn from the study. 
Fabrication of clay filled blended nanocomposites is possible by simple stir casting method. Sliding wear characteristics of clay filled blended nanocomposites are successfully analyzed using Taguchi's method. It concluded that the influencing parameters affecting Specific wear rate, of the composite specimen under sliding wear is as (i) Filler content (ii) Normal Load (iii) Sliding Velocity (iv) Sliding distance is the least significant control parameter. The clay filled blended nanocomposites showed better abrasion resistance under different abrading distances and at a given speed and load. This is because of the Filler interaction, Uniform dispersion and Lubricating qualities of the filler as a solid lubricant. Present investigation led to the conclusion that Polymer composites suitable for Engineering components subjected to wearing environments can be successfully prepared by filling in nanoclay, promising filler in Epoxy/VER blends. SEM micrograph suggests that the filling of blended nanocomposites in Epoxy changed the microstructure of the Epoxy/VER and prevented the destruction of matrix during friction process, acting as a solid lubricant. $b$ ) Presence of clay in Epoxy facilitated the formation of the transfer film, thereby reducing the wear rate; this was evident from the fact that, counterpart abrasion was absent, on the steel disc. The severe abrasive wear of $1 \mathrm{wt}$. \% clay filled blended nanocomposites has changed to mild fatigue wear with increasing clay content. Nano particles proved to be quite effective in lowering frictional coefficient and wear rate of the composite sliding against steel counterface.

\section{Acknowledgements}

Authors would like to thank the Principal in the RV College of Engineering, Bangalore for their timely help in providing laboratories.

\section{References}

[1] Lin D.K.J., Quality and Reliability Engineering International 10 (1994) 117-121.

[2] Zhang L.C., Zarudi I., Xiao K.Q., Wear 261 (2006) 806-811.

[3] Guang Shi, Ming Qui Zhang, Min Zhirong, Bernd Wetzel, Klaush Friedrich, Wear 254 (2003) 784-796.

[4] Xianhua Cheng, Yujun Xue, Chaoying Xie, Material Letters 57 (2003) 2553-2557.

[5] Witold Brostow, Wunpen Chonkaew, Kevin Menard, Thomas W. Scharf, Material Science and Engineering 10 (2009) 241-251.

[6] Suresha B., Ravishankar B. L., Sukanya L., Usak University Journal of Material Sciences 24 (2012) 79-94.

[7] Santram Chauhan, Sunil Thakur, JMMCE 11 (2012) 938-946.

[8] Bernd Wetzel, Frank Haupert, Ming Qui Zhang, Composite Science and Technology 63 (2003) 2055-2067.

[9] Guirong Peng, Lijun Gao, Zayi Zhan, Haifengweng, Wenguang Hao,. Polymer Bull. 63 (2009) 911-919.

[10] Shi-Quan L, Li Yue, Tong-Sheng Li, Zhi-Meng Hu, Wear 260 (2005) 462-468.

[11] Manoj Singla, Vikas Chawla, JMMCE 9 (2010) 199-210. 
[12] Suresha G., Chandra Mohan, Sadananda Rao P. R., Sampathkumarau P., Seetharumu S., Vartha Venkateswarlu, Indian Journal of Engineering \& Material Science 13 (2006) 535-541.

[13] Lingaraju D., Ramji K., Pramila M., Deviand U., Rajya Lakshmi, Bull. Mater. Sci. 34(4) (2011) 705-712.

[14] Chun Ki Lam, Kin Tak Lau, Letters 6 (2007) 3863-3866.

[15] Bernd Wetzel, Frank Haupert, Ming Qiu Zhang, Composites Sci. \& Tech. 2003; 63 (2003) 2055-2067.

[16] McCook N.L., Boesl B., Burris D.L., Sawyer W.G., Epoxy, Tribology letters 5 (2006) 1245-1250.

[17] Guang Shi, Ming Qui Zhang, Min Zhirong, Bernd Wetzel, Klaush Friedrich, Wear 254 (2003) 784-796.

[18] Suresha B., Chandramohan G., Prakash J.N., Balusami V., Shankaranarayanasamy K.,. Journal of Minerals and Materials Characterization \& Engineering 5(1) (2006) 87101.

[19] Zhang L.C., Zarudi I., Xiao K.Q., Wear 261 (2006) 806-811.

[20] Sidhu J.S., Lathkar G.S., Sharma S.B., Malaysian Polymer Journal 9(1) (2014) 24-32. 